\title{
O projeto sobre preexistências: Uma análise da obra do escritório Lacaton \& Vassal.
}

\author{
Maria Laura Ramos Rosenbusch
}

Mestranda pelo Programa de Pós-Graduação em Arquitetura da PUC-Rio

Contato: mlaurarr@gmail.com

\section{RESUMO}

O escritório de arquitetura francês Lacaton \& Vassal possui uma obra em que a apropriação de preexistências é recorrente: pela utilização de sistemas estruturais pré-fabricados de catálogo, pela incorporação do construído em projetos novos e pela permanência e manutenção do existente. Este artigo pretende analisar essas diferentes formas de apropriação e identificar novas motivaçôes críticas, dentro de um contexto contemporâneo, para o uso desta estratégia na concepçáo do projeto de arquitetura.

Palavras-chave: preexistência; apropriação; Lacaton \& Vassal.

\section{ABSTRACT}

French architectural office Lacaton \& Vassal owns a work in which the appropriation of preexistences is recurrent: through the use of commercial prefabricated structural systems, by incorporating the preexistent building to new projects, and through the permanence and maintenance of the existent building. This article is aimed to analyze such different appropriation methods and to recognize new critical motivations, within a contemporary context, for using this strategy in the conception of architectural projects.

Keywords: preexistences; appropriation; Lacaton \& Vassal. 
A consciência quanto à finitude dos recursos naturais e a percepção de que o padrão de produção e consumo continuamente em expansão não têm possibilidade de se manter, faz necessária uma mudança de paradigma no campo da arquitetura, assim como em outras áreas do conhecimento. $\mathrm{O}$ arquiteto contemporâneo trabalha em um mundo maciçamente construído com recursos naturais escassos e um enorme repertório de invençôes e situaçôes preexistentes. Neste sentido, a reutilização e a reinterpretaçáo de preexistências se apresentam como alternativa aos modos tradicionais da produção arquitetônica.

Como uma imagem desta mudança de paradigma, tomarei a definição de Nicolas Bourriaud, crítico de arte, curador e cofundador do Palais de Tokyo em Paris, do que ele chamou de arte da "pós-produção".

Pós-produção: um termo técnico utilizado no mundo da televisão, do cinema e do vídeo. Designa o conjunto de tratamentos dados a um material registrado: a montagem, o acréscimo de outras fontes visuais ou sonoras, as legendas, as vozes off, os efeitos especiais. Como conjunto de atividades ligadas ao mundo dos serviços e da reciclagem, a pós-produção faz parte do setor terciário em oposição ao setor industrial ou agrícola, que lida com a produção das matérias-primas. (BOURRIAUD, 2009, p. 7).

Aarte da pós-produção seria todaa arte contemporânea que não mais trabalha sobre uma matéria-prima bruta, mas sobre elementos existentes que circulam no mercado cultural. Seria uma maneira do artista se reorientar dentro do caos cultural contemporâneo e de extrair deste caos novas formas de produção.
Segundo o autor, a produção contemporânea não se ocupa mais de criar a partir de um material virgem ou de superar criaçóes do passado, como pretendia a ideologia modernista do novo, mas de encontrar novas narrativas, novos itinerários pela cultura existente. Estas novas narrativas, por sua vez, participarão de outras, em um movimento sem fim.

Assim também, no campo da arquitetura, o excesso da produção e o consequente crescimento descontrolado das grandes cidades também teve seus desdobramentos na maneira de projetar arquitetura. $\mathrm{O}$ arquiteto contemporâneo trabalha cada vez mais sobre espaços construídos e náo em territórios virgens, por isso, tornou-se muito importante decidir como atuar sobre o existente.

\section{Lacaton \& Vassal e o trabalho sobre preexistências}

"Não há mais páginas brancas. Temos de trabalhar com o que já existe. Isto está longe de ser algo negativo (...). As potencialidades e as capacidades do todo existente são integradas, reativadas e reutilizadas e enriquecem novos projetos. Todas as condicionantes podem ser transformadas positivamente."

Lacaton \& Vassal

Muitos teóricos afirmam que a obra do escritório francês Lacaton \& Vassal se constitui em uma prática crítica ao modo usual pelo qual se produz arquitetura. ${ }^{1} \mathrm{~A}$ partir desta constatação podemos nos perguntar: que aspectos fazem com que esta prática se constitua em crítica ou mesmo em transgressão? Para responder a esta questáo deve-se ter claro o momento histórico em que esta obra se encontra inserida, pois práticas que tensionam os limites das 
disciplinas e as convençôes de determinado contexto temporal e cultural são dependentes destes mesmos limites e convençôes e buscam redefini-los.

Sendo assim, Lacaton \& Vassal são arquitetos contemporâneos que iniciaram sua carreira em meados dos anos 1990, em um contexto no qual grande parte da arquitetura contemporânea centrou sua prática de modo a valorizar o seu caráter midiático; houve, assim, uma supervalorização da dimensão visual da arquitetura em detrimento de outras tantas - a arquitetura contemporânea é muitas vezes reduzida a ícones e imagens que circulam nos meios de comunicação em massa.

Em contribuição para este aspecto, nas últimas décadas, o tema da crise ecológica e o conceito de sustentabilidade ganharam destaque em decorrência das visíveis transformaçôes do ecossistema natural e das assustadoras previsóes para o futuro. Assim, muitas foram as reaçôes ao tema da crise ecológica dentro da disciplina da arquitetura: o retorno às técnicas rudimentares, a mimese da natureza, a busca do controle do impacto ambiental das edificaçóes e, principalmente, respostas meramente estilísticas sob o rótulo de "arquitetura verde".

A estratégia da apropriação, recorrente na obra da dupla, se apresenta como um elemento que ajuda a constituir o seu teor crítico, uma vez que faz com que os arquitetos se desprendam de certa obsessão com a forma arquitetônica. Este conceito questiona também a constante produção do novo e a substituição do existente por edifícios novos. Para Lacaton \& Vassal, o projeto deve ser sempre abordado como uma interferência em um contexto, de maneira a se opor à ideia moderna de tábula rasa. As intervençôes propostas pelo casal sempre geram sobreposições: o lugar existente e a nova intervenção.
"Reinvent: Enchanting the Existing" é o tema da palestra ministrada por Anne Lacaton na Universidade de Columbia, em que ela apresenta sua produçáo arquitetônica que lida com as preexistências. Tratarei aqui de algumas destas obras.

\section{O início}

Na obra de Lacaton \& Vassal, a incorporação de preexistências já estava presente em seu projeto mais antigo, a Casa em Niamey (1984), construída por Jean-Philippe Vassal durante a temporada em que viveu em Níger, país no norte da África, logo após concluir os estudos na Faculdade de Arquitetura de Bordeaux.

A qualidade central deste projeto está na observação e reinterpretação da maneira pela qual os habitantes locais constroem suas casas, uma vez que eles já adquiriram, com a experiência, alto conhecimento sobre a qualidade dos materiais, o clima e a natureza locais. Em países quentes como Níger, a arquitetura tem uma função e, consequentemente, uma materialidade e uma maneira de construir particulares. Construir pode ser tão simples quanto apenas fincar alguns galhos na areia formando um círculo, entortar suas pontas para configurar a forma do telhado, envolver esta estrutura na parte lateral por uma palha aberta o suficiente para o ar passar através dela e na parte superior cobrir com uma palha mais fina e densa para proteger da chuva. Esta é a cabana primitiva típica dos povos nômades habitantes do norte da África.

O projeto da casa construída por Vassal é composto basicamente desta cabana acrescida de outros espaços: este primeiro volume é envolvido por um segundo elemento, uma cerca de palha disposta no perímetro 
de um círculo com quinze metros de diâmetro, três vezes maior que o primeiro. A estes espaços, é acrescentado um terceiro que possui as qualidades de um pilotis, um espaço aberto feito de tocos de madeira cobertos com sacos de arroz costurados.

A dupla costuma iniciar suas palestras apresentando este projeto porque ele sintetiza o sentido de seu trabalho: a economia de recursos. A economia, segundo eles, é uma forma de evitarem se perder na "cultura da composição e da imagem, renunciando, definitivamente, a toda certeza, a todo preconceito estético. (...) seria uma forma de situar a arquitetura fora de sua existência plástica" (LACATON; VASSAL, 2011, p.173). Além disso, a diminuição do custo por metro quadrado permite que o projeto extrapole as demandas programáticas iniciais. Construir o dobro dos metros quadrados previstos no programa inicial é uma característica que vai se repetir em muitos projetos construídos posteriormente.

\section{Deslocamento: uma "correção tipológica"}

Tanto o projeto da Casa Coutras (2000) quanto o conjunto de habitaçóes Cité Manifeste (2005) são compostos pela apropriação de um objeto pronto que possui uma configuração formal e maneira própria de construção: a estufa agrícola.

A Casa Coutras pode ser descrita como duas estufas pré-fabricadas escolhidas em catálogo e construídas lado a lado; uma abriga o programa da casa e a outra é deixada vazia como um espaço sem uso definido. Os argumentos de Lacaton \& Vassal para justificar o uso de uma estrutura existente sempre privilegiam a economia e a ideia de construir o máximo de espaço possível permitindo a liberdade de usos.

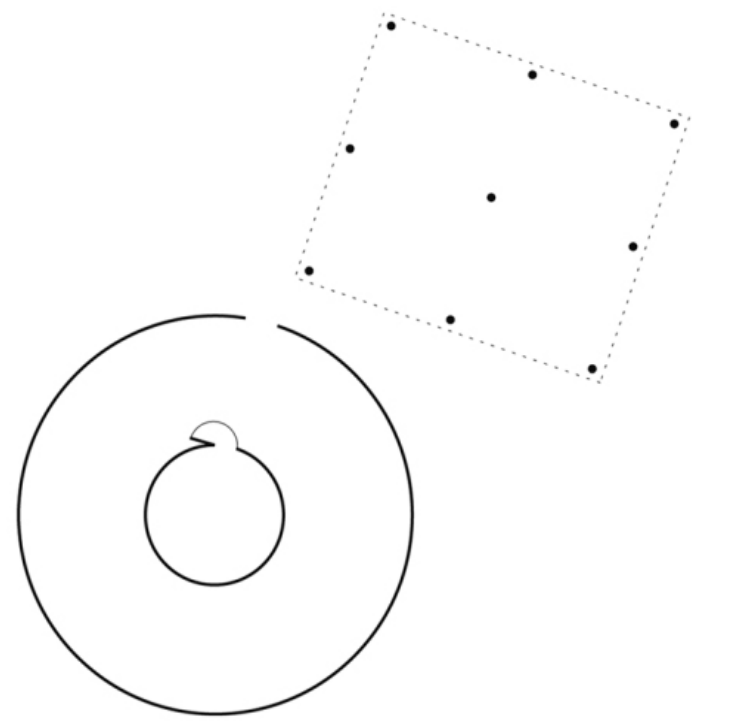

figura 1: Planta da casa em Niamey, projeto JeanPhilippe Vassal.

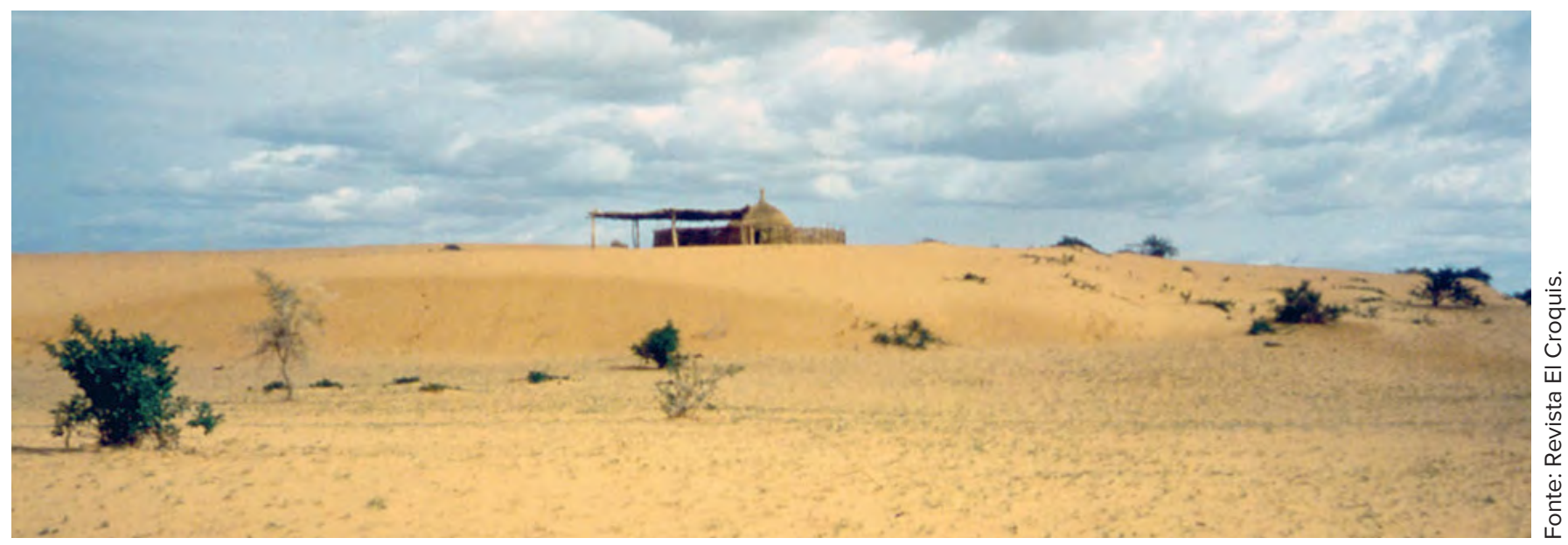

figura 2: Vista externa da casa em Niamey.

Revista online do Departamento de Arquitetura e Urbanismo da Pontifícia Universidade Católica -

Puc-Rio - Rio de Janeiro Brasil

Ano I- No I - ISSN 2446-7340 
Para este projeto, a justificativa não é diferente. Para os arquitetos a opção de usar uma estufa permitiu construir espaços maiores a baixo custo, oferecendo inúmeras possibilidades de utilização e adaptação, além de um conjunto variado de ambientes e sensaçóes.

Apesar da literalidade da composição final, modificaçóes devem ser feitas para tornar a estrutura adequada ao novo uso. Ou seja, a ideia de readymade domina o projeto da casa - os aspectos formais são consequência da função anterior do objeto, e não uma decisão específica para o projeto - porém, não a compóe inteiramente (CAPELA, 2013). Esta operação de Lacaton \& Vassal não se limita apenas à apropriação. Neste sentido, creio que ela se aproxima mais da ideia de pós-produção descrita por Bourriaud. $\mathrm{O}$ arquiteto pós-produtor (levando para o âmbito da arquitetura o termo de Bourriaud) apropria-se de elementos preexistentes e os reinterpreta. Segundo o autor, "a apropriação é a primeira fase da pósprodução: não se trata mais de fabricar um objeto, mas de escolher entre objetos existentes e utilizar ou modificar o item escolhido segundo uma intenção específica” (BOURRIAUD, 2009, p. 22).

Portanto, a estufa atua como uma caixa exterior para um volume interno que contém o programa da casa: uma sala, cozinha, três quartos e banheiros. Este volume em madeira complementa a estrutura da

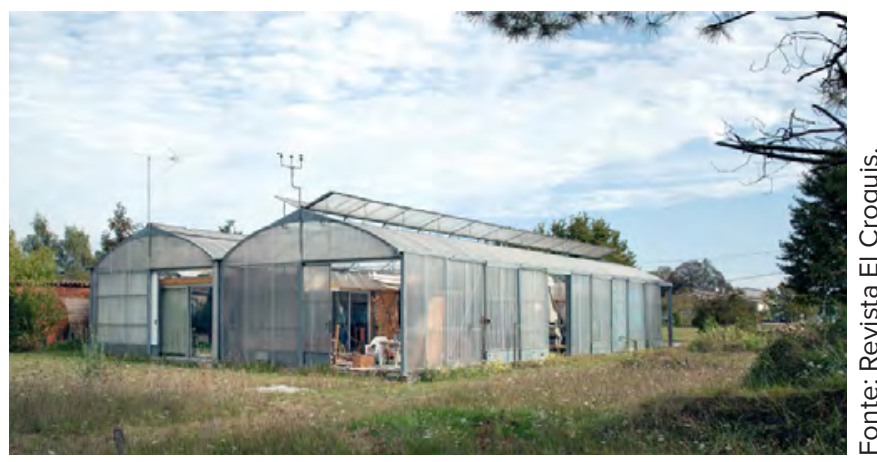

figura 3: Vista externa da Casa Coutras. estufa de forma a proporcionar a qualidade ambiental necessária para uma habitação: os fechamentos de madeira bloqueiam a insolação excessiva. Além disso, a pavimentaçáo do piso em concreto protege a casa da umidade, o forro do telhado isola o ambiente térmica e acusticamente e a camada de portas acrescentadas, além das portas da própria estufa, veda adequadamente o ambiente.

Mais do que a apropriação de duas estufas para uma moradia, o projeto é uma adaptação de um sistema para esse fim. Segundo o arquiteto Juan Herreros, em artigo publicado na revista El Croquis dedicada à obra de Lacaton \& Vassal:

Para além de oferecer tantos dos ingredientes sonhados pelos arquitetos do século XX - industrial, leve, lógico, sem grandes exigências estruturais, com vidros simples -, o que torna interessante a forma de agir de Lacaton $\&$ Vassal em face desse objeto mágico é como eles o destituem de sua funçáo verdadeira, que configura a lógica de seu sistema construtivo, para transformá-lo num tipo pronto para sua manipulação. Digamos que é preciso destituir a estufa da sua especificidade para poder trabalhar com ela; ou seja, ela precisa deixar de ser uma estufa. (HERREROS,

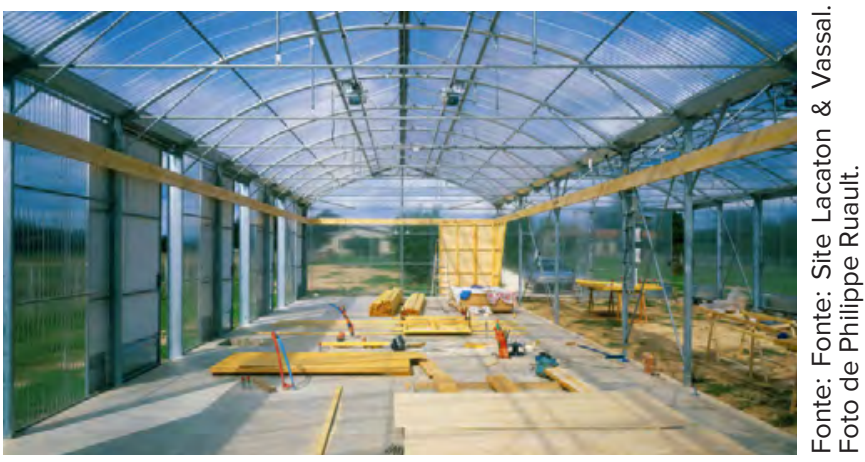

figura 4: Montagem da Casa Coutras.

Revista online do Departamento de Arquitetura e Urbanismo da Pontifícia Universidade Católica -

Puc-Rio - Rio de Janeiro Brasil

Ano I - N ${ }^{\circ}$ I - ISSN 2446-7340 


$$
\text { 2015, p. 362). }{ }^{2}
$$

Já no projeto para o edifício residencial Cité Manifeste ${ }^{3}$, eles combinam dois sistemas construtivos distintos: o primeiro, um sistema de pilares, vigas e lajes alveolares de concreto pré-fabricado que constitui o embasamento e, sobreposto a este, as estufas agrícolas. Tal embasamento foi usado pelos arquitetos de modo a se adequar ao tamanho das estufas: os módulos estruturais do pavimento térreo foram projetados para conformarem áreas de 3,00 x 6,40 metros, precisamente as dimensóes das estufas disponíveis no mercado. Nessa base estão localizadas as garagens, assim como as salas, os quartos e as dependências de serviço.

Sobreposta a esta estrutura em concreto, os arquitetos usam a mesma estratégia usada na casa em Coutras, porém, neste caso, em grande escala, pois são 14 unidades residenciais. Aqui, também, algumas estufas recebem tratamento térmico e acústico e outras não, funcionando como um jardim de inverno ou uma varanda.

Assim como em Coutras e Mulhouse, na Escola de Arquitetura de Nantes (2009) os arquitetos recorrem a um sistema construtivo pensado para outra tipologia, neste caso, um sistema típico de prédios de estacionamento (RUBY, 2015, p. 9). Esta decisão construtiva para a escola, segundo Ilka e Andreas Ruby, deve-se a dois motivos:

(...) em primeiro lugar, para permitir certos usos que não poderiam ser acomodados em uma escola construída de forma convencional (graças, em parte, à possibilidade de acesso de veículos até o telhado). Em segundo lugar, porque o sistema construtivo de um prédio de estacionamento é barato e custou a metade do orçamento disponível. A metade remanescente do orçamento permitiu a construção de um espaço extra, aproximadamente táo grande como o programa. (ILKA \& ANDREAS RUBY, 2007, p. 9). ${ }^{4}$

Juan Herreros chamou esta adaptação de "correção tipológica": uma manipulação de tipologias existentes que é em si um projeto. A estufa agrícola ou o estacionamento "corrigidos" por Lacaton \& Vassal são uma demonstração do que pode acontecer a tudo o que foi construído diante das transformaçóes e incertezas quanto ao uso no futuro. Segundo Herreros, a ideia tradicional de flexibilidade segundo a qual os edifícios devem estar preparados

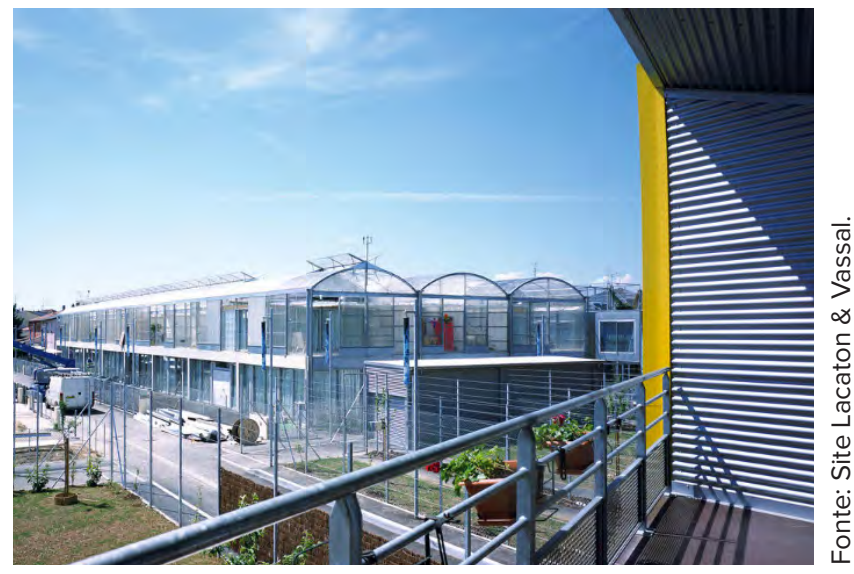

figura 5 e 6: Legenda para ambas figuras: Projeto Cité Manifeste.

Revista online do Departamento de Arquitetura e Urbanismo da Pontifícia Universidade Católica -

Puc-Rio - Rio de Janeiro Brasil

Ano I- N ${ }^{\circ}$ I - ISSN 2446-7340 
para mudanças previsíveis - uma nova organização dos postos de trabalho ou o aumento ou reduçáo dos membros de uma família - é substituída pela incerteza que acompanha as mudanças imprevisíveis que as novas tecnologias trarão ao uso dos espaços. Ou seja, é algo muito mais indefinido que nos obriga a deixar projetos abertos ao desconhecido. (HERREROS, 2015, p. 362). Neste sentido, a arquitetura de Lacaton \& Vassal pode ser entendida apenas como envoltórios ocupados, ou seja, a ideia de apropriação não está presente apenas na maneira como projetam, apropriando-se de preexistências, como também no projeto de estruturas suficientemente abertas que permitem diversas apropriaçóes futuras para diversos usos.

\section{Sobreposição e manutençáo dos espaços construídos}

Outra forma de apropriação de preexistências em Lacaton \& Vassal seria a sobreposição de estruturas novas a estruturas existentes. Por exemplo, o projeto realizado junto com Frédéric Drout para uma série de intervenções em edifícios residenciais existentes detalhadas no livro "Plus - La vivienda colectiva, territorio de excepción”. Estes projetos revelam de forma evidente a sobreposição de duas temporalidades - o projeto novo e o existente. Este conjunto de intervençóes está inserido em um contexto no qual o governo da França tinha um projeto de renovaçáo em grande escala baseado na demolição de conjuntos habitacionais dos anos 1960 e 1970 e na construção de novas habitaçóes (DRUOT; LACATON; VASSAL, 2007).

Diante desta demanda, os arquitetos se questionam quanto à demolição e argumentam:
Neste contexto [da França], em que se observa um importante déficit de habitação pública, consideramos que a demolição é uma aberração e a reabilitação dos edifícios permitirá responder às necessidades de uma forma mais econômica, eficaz e qualitativa. (...). Na maioria das vezes, o potencial estrutural, geográfico e espacial destes grandes edifícios é um valioso ponto de partida para melhorar radicalmente as atuais condiçôes das habitações. (DRUOT; LACATON; VASSAL, 2007)..$^{5}$

Lacaton \& Vassal iniciam assim uma campanha demonstrando como o dinheiro usado para a demolição e reconstruçáo poderia ser usado de uma forma muito mais eficiente para a conservação e manutenção a longo prazo destas edificaçôes. A dupla entende que a demolição é um desperdício, além de ser um transtorno para quem vive nestes edifícios. Segundo os arquitetos: "nunca construiríamos aqueles edifícios enormes, mas já que existem, não há necessidade de demoli-los. É uma questão pragmática e até ecológica" (LACATON; VASSAL, 2016).

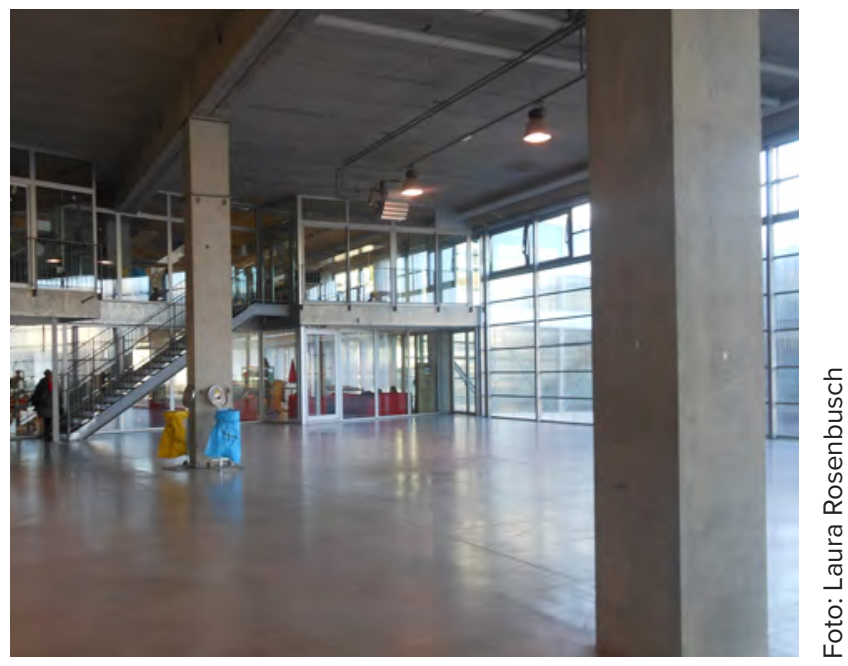

fig. 7: Projeto da faculdade de arquitetura de Nantes 


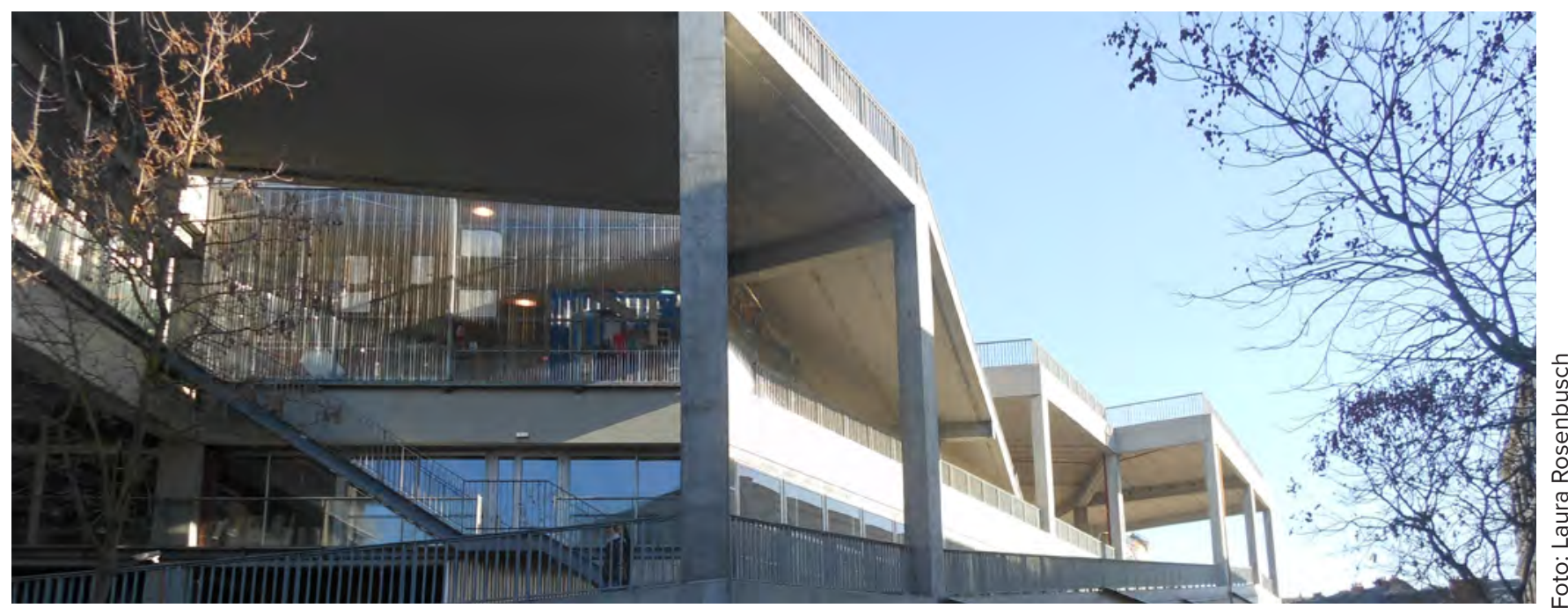

figura 7 e 8: Projeto Faculdade de arquitetura de Nantes.

Assim, Lacaton \& Vassal optam por não demolir, mas modificar internamente com a participação dos moradores e acrescentar estruturas novas que se acoplam à fachada dos edifícios existentes. A antiga fachada com fechamento em alvenaria e pequenas janelas é substituída por portas de vidro que dão acesso a um espaço acrescido - uma varanda com duas qualidades ambientais, uma parte com um fechamento em telha ondulada e outra totalmente aberta. Este acréscimo amplia significativamente os apartamentos, transformando o modo como a planta original é usada e fornecendo novas conexóes entres os ambientes.

Ilka e Andreas Ruby, na introdução do livro "Plus - La vivienda colectiva, territorio de excepción", consideram ser altamente ideológica a noção de que certos edifícios antigos devem ser preservados ou até reconstruídos tal como eram originalmente, desconsiderando sua trajetória ao longo do tempo, enquanto outros devem ser demolidos. Assim, os autores entendem que é pela simbologia negativa que estas torres carregavam que o governo da França entendeu que deveriam ser derrubadas e construídas residências individuais.
Portanto, na intervenção de Lacaton \& Vassal está implícita a ideia de que os edifícios devem ser considerados como objetos em si, náo cabendo à época atual a escolha dos elementos da história que se pretende manter e aqueles que devem ser esquecidos. Ao contrário, todo edifício existente possui um potencial de reinterpretação que os arquitetos contemporâneos devem aproveitar.

Já no projeto para a praça Léon Aucoc (1996) em Bordeaux, a ideia de manutenção do existente é expressa de maneira ainda mais radical. Ao serem incluídos em um programa do município de Bordeaux para embelezar as praças e espaços públicos da cidade, Lacaton \& Vassal respondem a este encargo com um texto no qual descrevem um processo de observação, avaliação e consulta local:

$\mathrm{Na}$ nossa primeira visita, tivemos a sensação de que esta praça já é bonita, por ser autêntica e sem sofisticação. Possui a beleza do óbvio, do necessário, do adequado. Seu sentido é direto. As pessoas se sentem em casa ali, em uma atmosfera de harmonia e tranquilidade construída ao longo de muitos anos. Nós

Revista online do Departamento de Arquitetura e Urbanismo da Pontifícia Universidade Católica -

Puc-Rio - Rio de Janeiro Brasil

Ano I - N I - ISSN 2446-7340 
passamos algum tempo assistindo o que acontecia lá e conversamos com alguns dos moradores locais. Nos perguntamos sobre a necessidade de um projeto para esta praça visando seu embelezamento. O que seria a ideia de "embelezamento"? Trata-se de substituir um tratamento de piso por outro? Substituir um banco de madeira por um design mais "upto-date" em pedra? Ou um padrão de iluminação por outro mais elegante? Nada ali exigia muitas mudanças e a ideia de embelezamento não tinha lugar. (...) A praça já era bonita. Como projeto nós propusemos fazer nada além de alguns trabalhos de manutenção simples

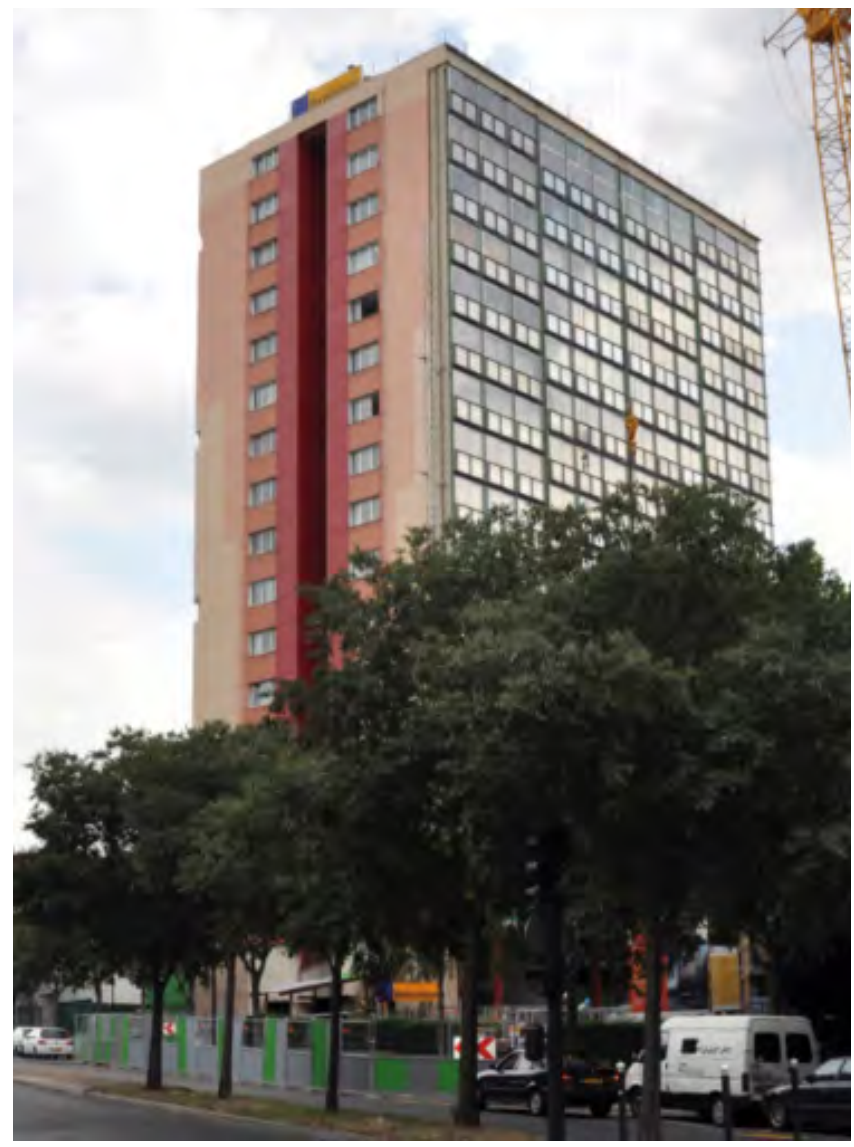

figura 9: Tour Bois le Prêtre antes da intervençâo de Lacaton \& Vassal. e rápidos - substituindo o cascalho, limpando a praça mais frequentemente, tratando os tijolos, modificando o tráfego ligeiramente para melhorar o uso da praça e para satisfazer a população local. (LACATON; VASSAL, 2002, p. 30-31).

O texto é um elogio à praça como forma de justificar que nada mais era necessário, apenas a sua manutenção. Assim, em resposta ao encargo de "embelezamento" da praça, resolvem "não propor nada”, pois consideram que a praça "já era bonita”.

Em concordância com esta atitude dos arquitetos, Ińaki Ábalos, no artigo "Bartleby el arquitecto" faz uma crítica à arquitetura contemporânea

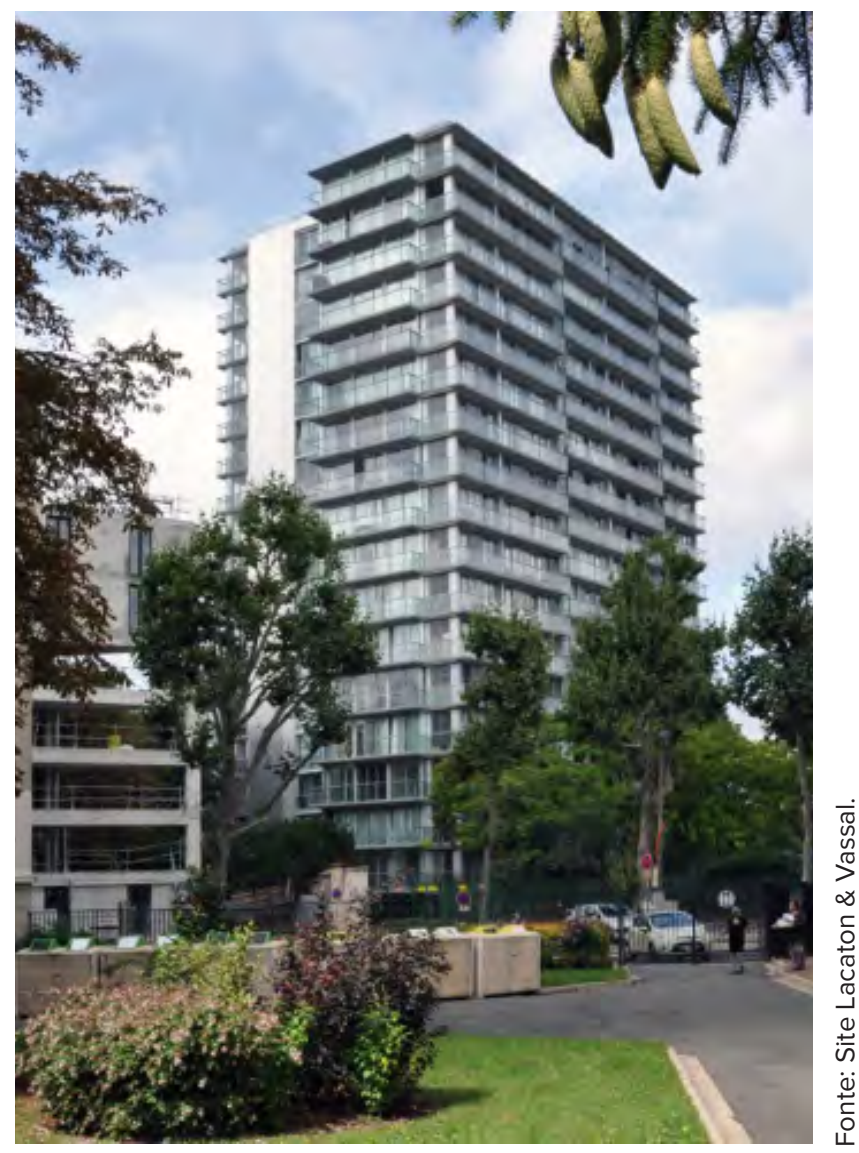

figura 10: Tour Bois le Prêtre após a intervenção de Lacaton \& Vassal.

Revista online do Departamento de Arquitetura e Urbanismo da Pontifícia Universidade Católica -

Puc-Rio - Rio de Janeiro Brasil

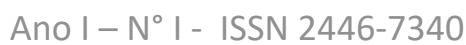


denominada "sustentável”. Segundo ele, os arquitetos contemporâneos, na ânsia de responder a questôes ambientais, econômicas e sociais "sem afetar os orçamentos e sem pôr em crise o modelo de cidadenegócio" e preocupados com o valor de mercado deste novo rótulo do "sustentável", vinculam o termo a projetos incipientes até esvaziá-lo totalmente de significado. Para Ábalos, o arquiteto contemporâneo preocupado com a sustentabilidade deveria se comportar como Bartleby, personagem criado por Herman Melville, um escrivão que repete sua famosa frase "preferiria não fazê-lo" cada vez que é solicitado para algum trabalho. Lacaton \& Vassal têm uma atitude semelhante: ao questionar a necessidade de qualquer ação, muitas vezes "preferem não fazer" diante de demandas que consideram desnecessárias (ABALOS, 2007).

Já Robin Wilson escreve na revista "The Architecture of Transgression" que é a estratégia da "manutenção" em vez da "não ação" que constitui o termo crítico e transgressivo no projeto de Lacaton \& Vassal para a praça Léon Aucoc. Segundo ele, não se trata simplesmente de náo fazer nada, mas de aproveitar os laços econômicos entre os arquitetos e o órgáo público para levar investimentos diretamente para

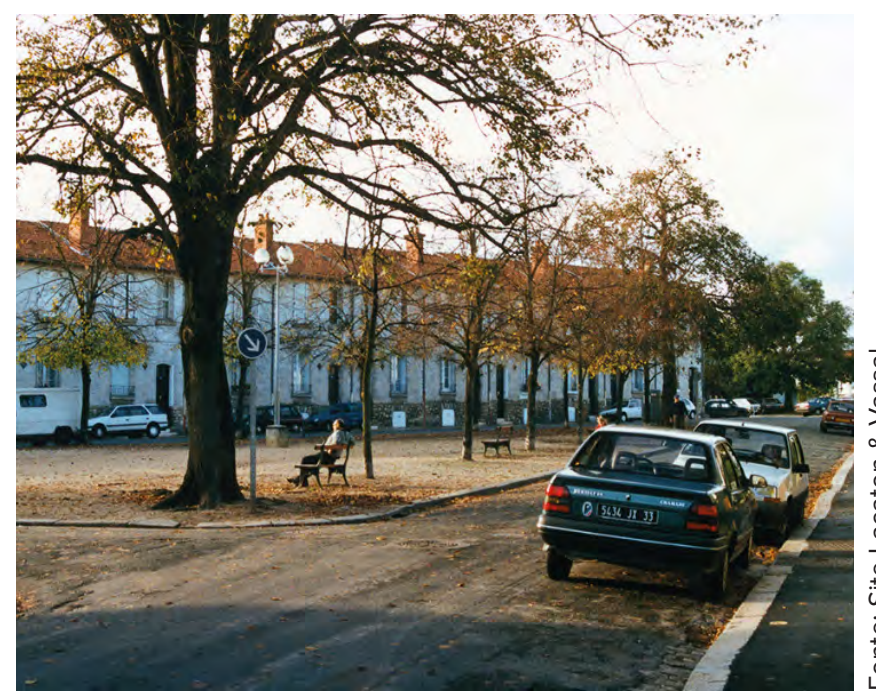

figura 11 :Projeto Praça Léon Aucoc. os cidadãos. Lacaton \& Vassal evitam produzir uma presença do órgáo público no local de forma meramente simbólica através do design; a solução dos arquitetos é dispersar o investimento em vez de concentrá-lo na fabricação de um novo objeto (como poderia ser a proposta de um novo mobiliário urbano para a praça), distribuindo assim o orçamento disponível em todo o tecido da praça e ao longo do tempo através de um programa de manutenção (WILSON, 2013).

\section{A ocupação de estruturas existentes}

Por último, na obra destes arquitetos há o entendimento de que estruturas existentes podem ser ocupadas constantemente para novos usos, o que está mais evidenciado em seu projeto para o Palais de Tokyo. Este projeto é uma intervenção no interior da ala oeste do conjunto edificado a partir de um concurso realizado em 1934 e inaugurado em 1937 para a Exposição Universal de Paris. O programa deste concurso pedia aos arquitetos que projetassem um conjunto com dois museus: o Museu Nacional de Arte Moderna e o Museu de Arte Moderna de Paris. O edifício é composto por duas alas simétricas; enquanto a ala leste continuou abrigando o Museu de Arte Moderna de Paris, a ala oeste, onde hoje se instala o Palais de Tokyo / Site de création contemporaine, teve diversos usos ao longo do tempo. Em 1995 foi iniciado um projeto de reforma do interior do edifício para que este abrigasse o Palais du Cinéma. Nesse momento, o interior do edifício foi parcialmente demolido para ser posteriormente reconstruído de acordo com o novo projeto, mas esse projeto foi abandonado alguns anos depois.

Já em 1999 foi lançado um novo concurso com o objetivo de transformar parte da ala desocupada

Revista online do Departamento de Arquitetura e Urbanismo da Pontifícia Universidade Católica -

Puc-Rio - Rio de Janeiro Brasil

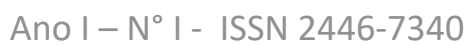


num centro temporário de criação para produção artística contemporânea. Lacaton \& Vassal vencem este concurso ao proporem conceitualmente a manutenção do espaço tal como o haviam encontrado, mantendo os resquícios do processo da reforma que não fora concluída. Para Lacaton $\&$ Vassal as demoliçóes feitas anteriormente revelavam a estrutura em concreto armado com suas amplas dimensóes e tornavam a luz natural abundante, entrando por grandes janelas de diferentes alturas e pelas claraboias, permeando os espaços internos sem encontrar barreiras. Segundo eles "a arquitetura já estava lá", não era necessário acrescentar nada mais, apenas potencializar as qualidades encontradas, concentrando seus esforços em reabilitar a estrutura para que o espaço pudesse ser usado novamente. O Palais de Tokyo foi reaberto em 2001 e dez anos depois, Lacaton \& Vassal foram chamados para uma segunda fase da intervenção, desta vez uma intervenção permanente, que consistiu na ampliação dos espaços de exposiçáo. Com isto, toda a ala oeste passou a abrigar o Palais de Tokyo.

Podemos entender o caráter inacabado e mínimo desta intervenção como algo que se relaciona, tanto do ponto de vista estético quanto por sua estratégia de ação, com as ocupaçóes (sem autorização) de edifícios ou espaços públicos. Segundo Jean Phillipe Vassal, suas açóes no Palais de Tokyo

... seguiram a lógica de uma ocupação - um ocupante em busca de abrigo num prédio industrial de 10.000 metros quadrados náo começa perguntando-se como reformar a área toda. $\mathrm{O}$ ocupante procura um lugar onde dormir e sentir-se seguro. Com o tempo, essa pessoa pode vir a ampliar esse espaço e talvez acabe por ocupar 100 metros quadrados. Entáo talvez chegue outro ocupante, e assim por diante. No Palais de Tokyo, nós adotamos um enfoque similarmente instintivo quanto ao espaço (LACATON; VASSAL, 2012, p. 18). ${ }^{6}$

Assim como na praça Léon Aucoc, a atuação dos arquitetos consistiu em distribuir o investimento em toda a área do edifício, com o "risco" de que estas intervençóes fossem pouco percebidas ou mesmo invisíveis. São projetos que se configuram como a manutenção de um espaço no sentido de manter o que está construído no lugar de construir algo novo e no sentido de investir na manutenção ao longo do

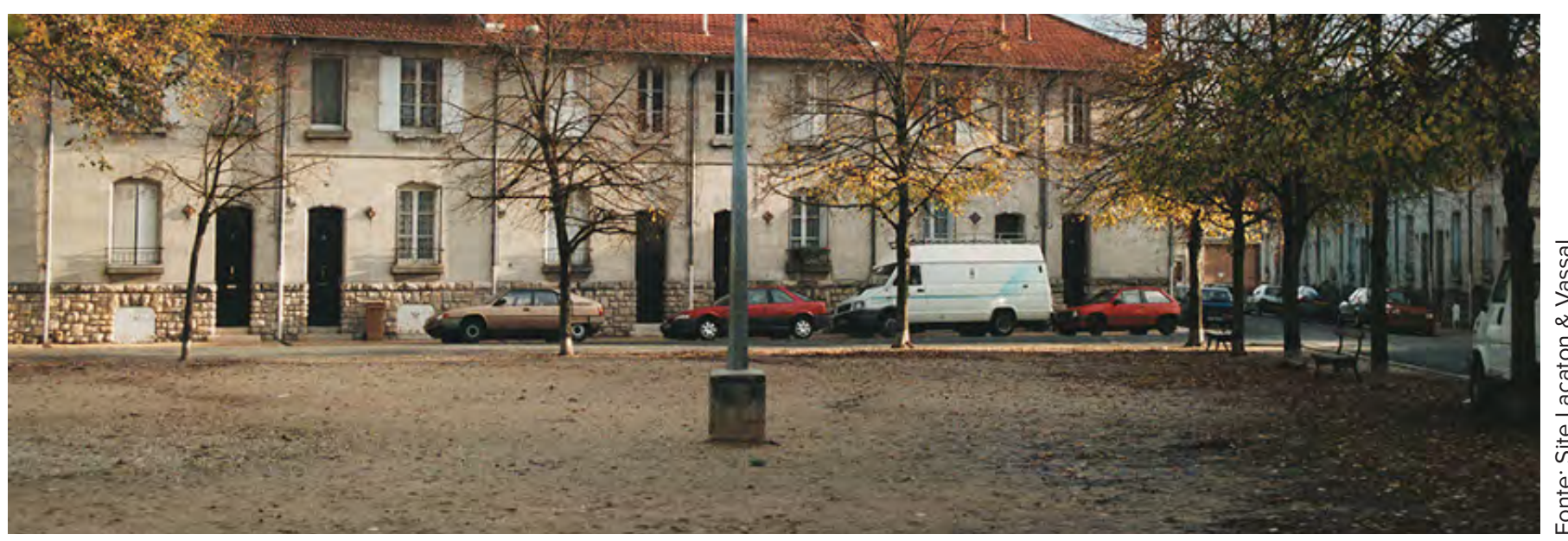

figura 12 :Projeto Praça Léon Aucoc.

Revista online do Departamento de Arquitetura e Urbanismo da Pontifícia Universidade Católica -

Puc-Rio - Rio de Janeiro Brasil

Ano I- Nº - ISSN 2446-7340 
tempo por meio de reparos mínimos necessários.

Concluindo, as novas motivaçóes e significados dados por Lacaton \& Vassal à estratégia da apropriação de preexistências, nos projetos apresentados, seriam respostas críticas à arbitrariedade da supervalorização da forma arquitetônica ou do tratamento apenas estético da arquitetura contemporânea comumente dita ecológica.

No âmbito da arte, a estratégia da apropriação inicialmente se apresentou como um questionamento dos paradigmas presentes na tradição do fazer artístico, tais como originalidade e autoria. Da apropriação derivaram conceitos como, "releituras", "reproduçôes”, "reinterpretaçôes”, "adaptaçôes" - conceitos que estáo relacionados ao trabalho artístico feito a partir de outro trabalho existente. Atualmente, a apropriação ganhou também uma dimensão ecológica e, neste sentido, dela derivaram outros conceitos, tais como "reuso" ou "reciclagem" - se trata de aproveitar o construído e propor o novo apenas quando necessário, o que está ligado a uma ideia de economia. Revalorizar o ambiente construído das grandes cidades e os elementos preexistentes em geral seria uma atitude de reação à renovação urbana sem questionamento, às demoliçóes,

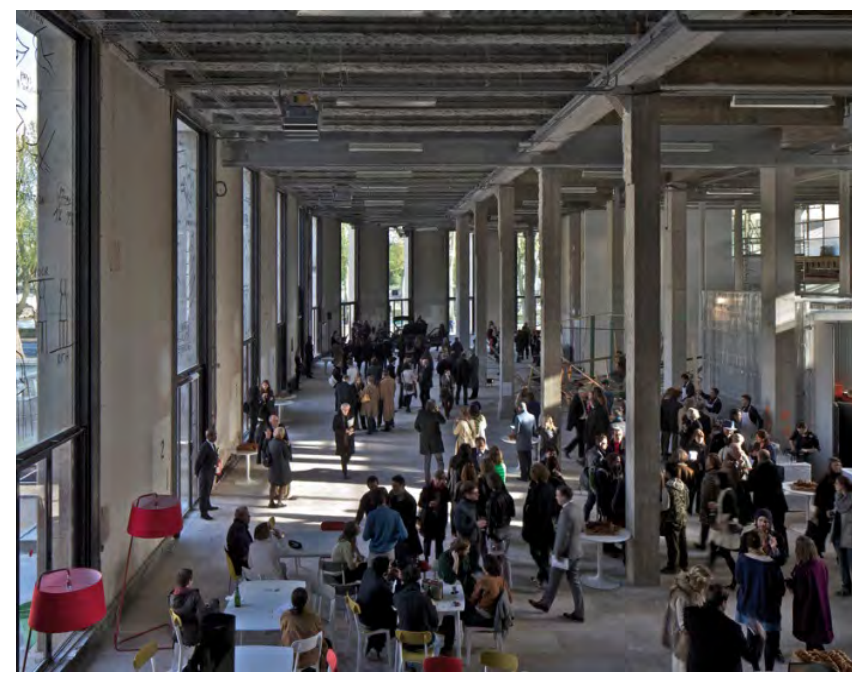

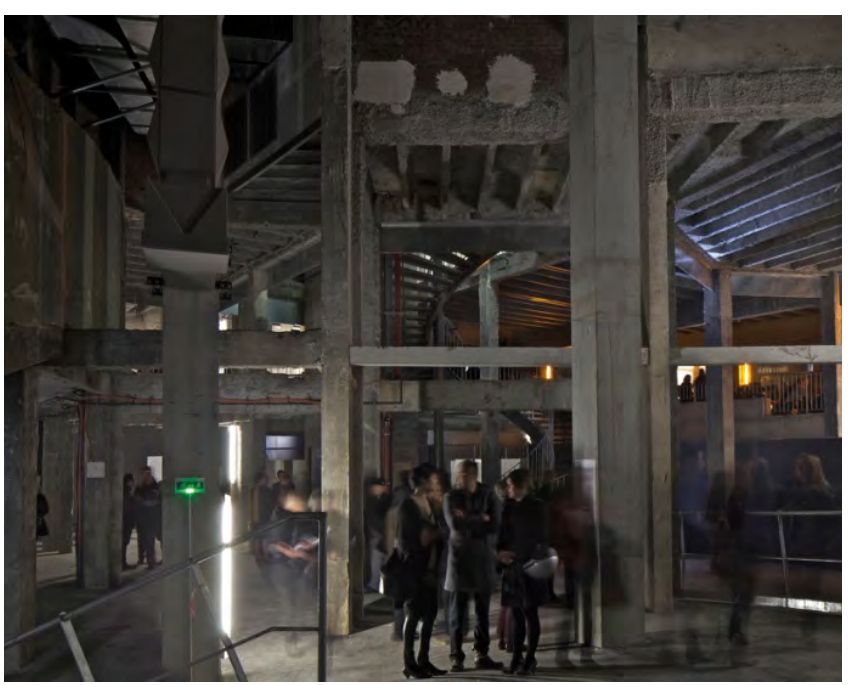
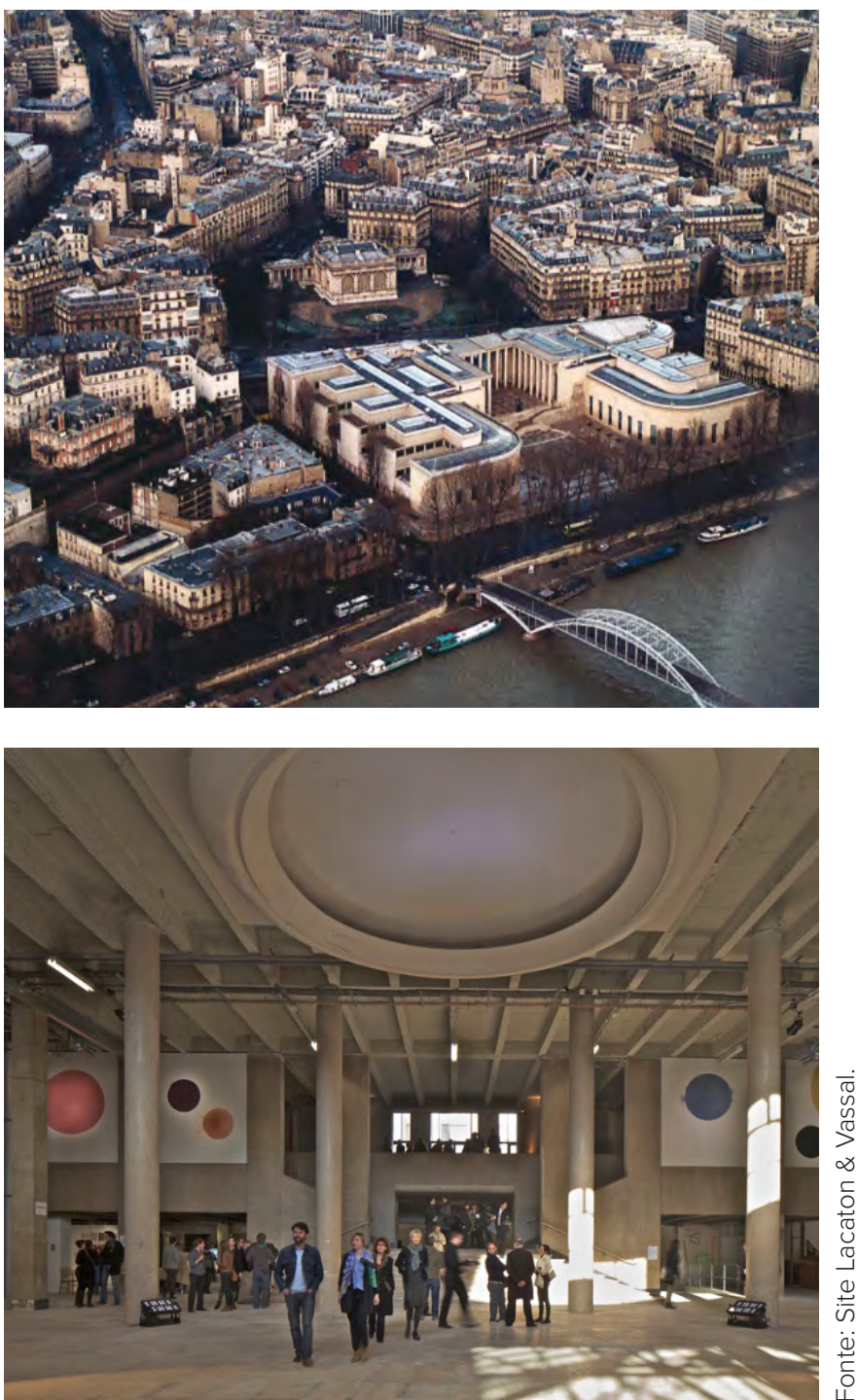

figura 13,14,15 e 16 :Palais de Tokyo.

Revista online do Departamento de Arquitetura e Urbanismo da Pontifícia Universidade Católica -

Puc-Rio - Rio de Janeiro Brasil

Ano I - NI - ISSN 2446-7340 
à produção desenfreada e ao desperdício característico do último século.

Assim, na obra de Lacaton \& Vassal a manutenção do existente não atende a uma vontade de preservação do passado nem à afirmação de uma identidade, mas a um entendimento da construção da cidade mediante a acumulação ou adição unida a uma preocupação ecológica. Certamente, sua arquitetura não é ecológica de maneira óbvia. Se a apropriação de preexistências fala de uma economia de recursos ao buscar ressignificar as edificaçóes existentes, por outro lado, estes arquitetos buscam sempre construir o dobro dos metros quadrados previstos pelo programa inicial e utilizam materiais baratos com baixa resistência aos processos de deterioração, o que a princípio, são atitudes que parecem contrariar uma lógica econômica. Porém, o que se revela na análise de sua obra é a vontade de se desvencilhar de muitos preconceitos estéticos e de um certo padrão de qualidade da arquitetura, quanto aos seus acabamentos, amplamente assimilados. Assim, o aspecto cru dos materiais utilizados por Lacaton $\&$ Vassal não fala de uma "verdade dos materiais", mas de um pragmatismo em tratar problemas a serem solucionados pela arquitetura de forma econômica. A abordagem da sustentabilidade nesta obra se dá pela crítica à cultura do novo tornando o velho obsoleto e à estética desconectada da necessidade.

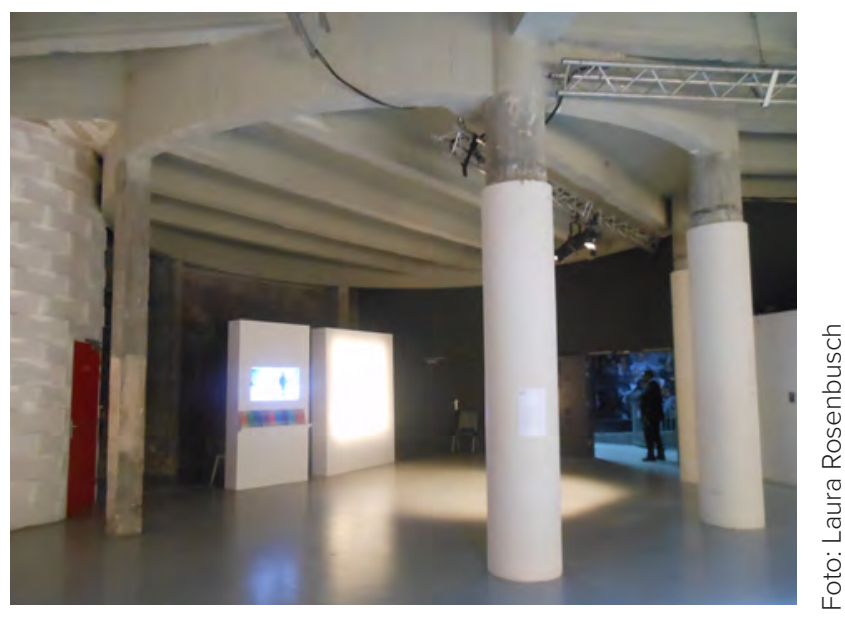

figura 17 :Palais de Tokyo. Colunas engordadas para reforçar a estrutura

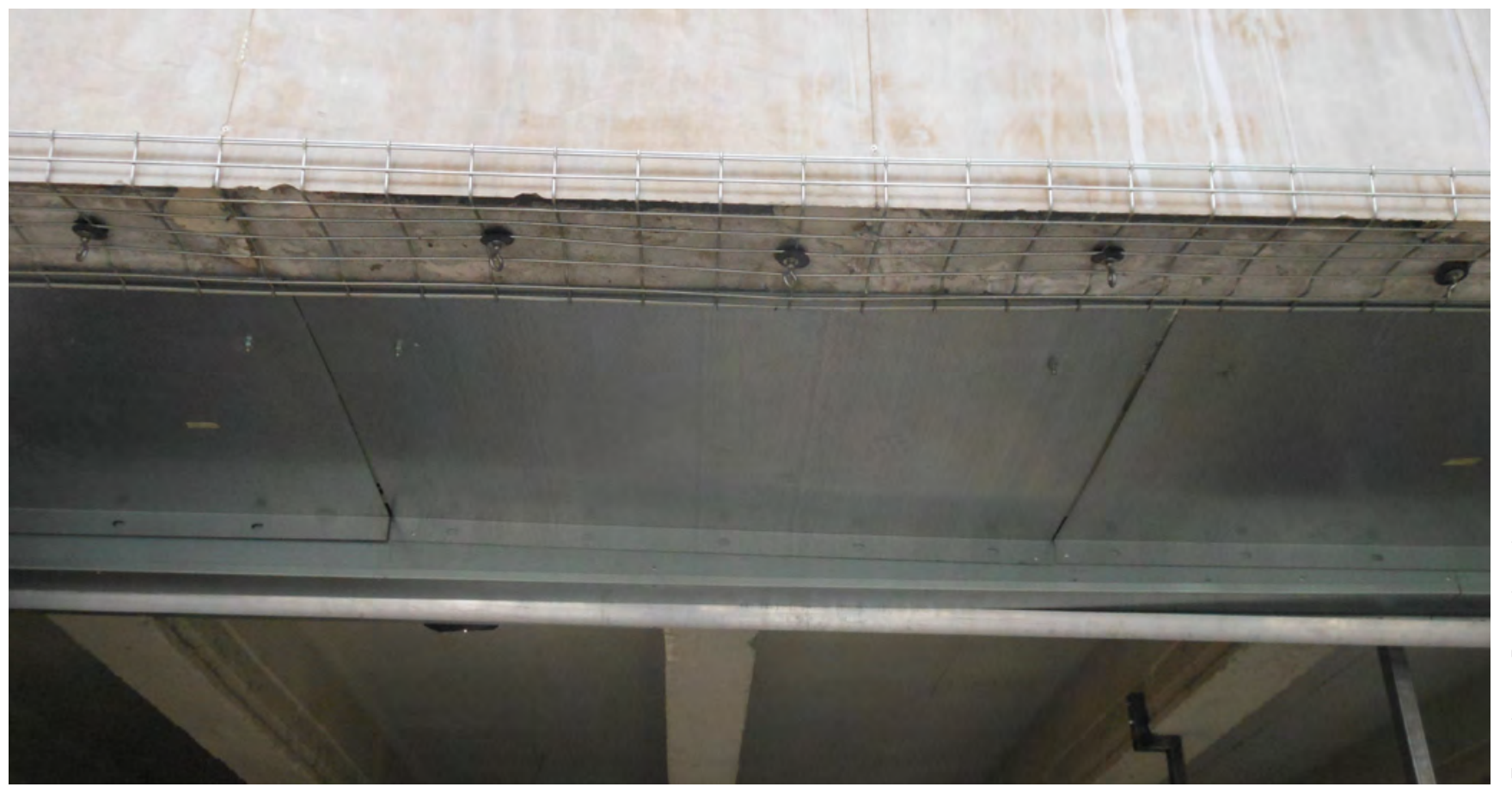

figura 18: Palais de Tokyo. Trama metálica para sustentar o revestimento em mármore existente.

Revista online do Departamento de Arquitetura e Urbanismo da Pontifícia Universidade Católica -

Puc-Rio - Rio de Janeiro Brasil

Ano I- No I - ISSN 2446-7340 


\section{Notas de fim}

1. A obra de Lacaton \& Vassal está incluída na publicação

da Architectural Design intitulada "The Architecture of Transgression" (juntamente com EXYZT, Didier Faustino, N55, Wang Shu, Superflex, Bernard Tschumi, Lina Bo Bardi, entre outros). Ver: SARA, Rachel (editora). Architectural Design, Vol. 83, n. 6. The Architecture of Transgression, 2014.

2.Traduzido pela autora. "Más allá de ofrecer tantos de los ingredientes soñados por los arquitectos del siglo $\mathrm{XX}$-industrial, ligero, lógico, sin grosores aislantes, sin grandes exigencias estructurales, con vidrios simples...-, lo que hace interesante la forma de proceder de L\&V frente a este objeto mágico es la forma en que lo despojan de su función verdadera, que es la que conforma la lógica de su sistema constructivo, para convertirlo en un tipo listo para su manipulación. Digamos que es necesario despojar al invernadero de su especificidad para poder trabajar con él; en definitiva, necesita dejar de ser un invernadero."

3. Este projeto faz parte de um conjunto maior de novas habitaçôes que foram criadas por cinco escritórios: Jean Nouvel, Poitevin \& Raynaud, Lewis+Block, Lacaton \& Vassal, Shigeru Ban \& De Gastines

4. Traduzido pela autora. "en primero lugar, para permitir ciertos usos que no puede alojar una escuela construida de modo convencional (gracias, en parte, a la posibilidad de acceso de trafico rodado hasta la cubierta). En segundo lugar, porque el sistema constructivo para un edificio de aparcamientos es barato y permitía la mitad del presupuesto disponible. La mitad restante del presupuesto permitió la construcción del espacio extra, aproximadamente tan grande como el programa."
5. Traduzido pela autora. "In this context, we consider that demolition is aberrant and that transformation would permit one to respond to needs in a more economic, more effective and more qualitative way. While today the high-rise estates present housing conditions that are more often than not unsatisfactory and inadequate, we are nevertheless convinced that a potential for quality remains associated with them." Disponível em https://www.lacatonvassal.com/index.php?i$\mathrm{dp}=46 \#$. Acessado em 30/04/18.

6.Traduzido pela autora. "It followed the logic of a squat - a squatter seeking shelter on a 10,000-square-meter factory building does not start wondering how to renovate the entire area. That squatter is looking for a place to bed down and feel safe. Over time, he or she might extend that space and maybe end up occupying 100 square meters. Then another squatter might arrive, and so on. In the Palais de Tokyo we took a similarly instinctive approach to the space."

7. Importante conceito para a arquitetura moderna, em especial da corrente conhecida como "brutalismo". Trabalhar sob a ideia de "verdade dos materiais" significa que cada material deve ser utilizado sempre de forma crua, sem pinturas ou revestimentos, de acordo com sua lógica estrutural e valorizando sua expressão plástica. Além disso, a forma de construir deve estar explícita na composição arquitetônica final - a ideia de beleza na arquitetura brutalista está associada à sua verdade construtiva. 


\section{Referências Bibliográficas:}

2G International Architecture Magazine, N.60 Lacaton \& Vassal, 2012.

ABALOS, Ińaki. Bartleby o arquiteto. Jornal El Pais, Madri, 10/3/2007.

BOURRIAUD, Nicolas. Pós-produção: como a arte reprograma o mundo contemporâneo. $1^{\text {a }}$ ed. São Paulo: Martins Editora, 2009.

CAPELA, José Manuel do Couto Ramos. Operating conceptually in art; Operating conceptually in architecture. Tese de doutorado em arquitetura. Braga: Universidade do Minho, 2013.

HERREROS, Juan. Nada Excepcional Siete Acciones Revisitadas en la Obra de Lacaton \& Vassal. El Croquis n.177/178. Lacaton \& Vassal, 2015.

DROUT, LACATON, VASSAL, Plus. La vivienda colectiva. Territorio de excepción. Editora Gustavo Gili, Barcelona, 2007.

LACATON, Anne. Reinvent: Enchanting the Existing. Palestra na Universidade de Columbia, 05/03/2013. Disponível em: https://www.youtube.com/ watch?v=pRkR8cXxC0g. Acesso em: 24/2/2018

LACATON, Anne; VASSAL, Jean-Philippe. "Libertad Estructural: condición del milagro". Revista 2G, Barcelona, no 60, 2011.

. In: Lacaton \& Vassal, 2G, No 21.

Barcelona: Editorial Gustavo Gili, 2002.
. "Arquiteturaéum ato de generosidade".

Entrevista concedida ao Expresso em 15/11/2016. Disponível em: http://expresso.sapo.pt/cultura/2016-0915-Arquitetura-e-um-ato-de-generosidade\#gs.=sQZYvo. Acesso em: 29/2/2018.

"School of architecture, Nantes", 2000. Disponível em: <https://www.lacatonvassal.com/ index.php?idp=16\#>. Acesso em: 30/5/2017.

"Reduce, Reuse, Recycle", Veneza,

2012. P. 13-26. Disponível em:

https://www.lacatonvassal.com/data/documents/2013041518380412ReduceReuseRecycle.pdf.

RUBY, Ilka, RUBY, Andreas. Extra Space, Extra Large on the recent work of Lacaton \& Vassal, In: GILI, Mónica; PUENTE, Moisés; PUYUELO, Anna (eds.). Lacaton \& Vassal 2G Books. Barcelona: Gustavo Gili, 2007.

VARELLA, Pedro; Lassance, Guilherme (Orientador) Estrutura aberta: o caso da Escola de Arquitetura de Nantes, projeto de Lacaton \& Vassal. Rio de Janeiro, 2016. Dissertação de Mestrado - PROARQ, Universidade Federal do Rio de Janeiro.

WILSON. Robin. Not Doing / Overdoing: 'Omission' and 'Excess'. Lacaton \& Vassal's Place Léon Aucoc, Bordeaux, and Construire's Le Channel, Scène Nationale de Calais, Calais. Architectural Design, [s.l.], v. 83, n. 6, p. 4451, nov. 2013. Wiley-Blackwell. Disponível em: http:// dx.doi.org/10.1002/ad.1673. Acesso em: 17/3/2018. 